\title{
Arqueologia, comunidade, ancestralidade e outros assuntos para pensar a identidade quilombola
}

\author{
Fabio Guaraldo Almeida* \\ Michelle Borges Pedroso** \\ Silvio Campos***
}

\begin{abstract}
ALMEIDA, F.G.; PEDROSO, M.B.; CAMPOS, S. Arqueologia, comunidade, ancestralidade e outros assuntos para pensar a identidade quilombola. R. Museu Arq. Etn. 34: 194-205, 2020.

Resumo: O mote da IV Semana Internacional de Arqueologia - Discentes MAE/USP girou em torno da pluralização de debates a partir de perspectivas que enfatizassem a preocupação com contextos sociais e culturais marginalizados pelas sociedades, pelos estudos, pelas instituições etc. A periferia se tornou centro e as discussões foram construídas a partir de problemas de sujeitos e contextos esquecidos e apagados. Assim, enfatizamos a importância de falar sobre os que estão às margens, e, mais ainda, sobre a importância de deixar que eles mesmos falem e criem possibilidades para que suas vozes sejam ouvidas. A mesa "Arqueologias Quilombolas" promoveu o debate entre diferentes perspectivas. A presença de Silvio Campos, junto às demais pesquisadoras, confirma a urgência de repensarmos nossas estruturas universitárias hierárquicas. Nós precisamos promover e valorizar outras formas de produção de conhecimento e perceber que sempre temos muito a ensinar, mas temos muito mais a aprender com os outros. Silvio nos ensinou sobre sua comunidade a partir de suas narrativas, saberes e vivências. Depois de sua participação na mesa, conversamos um pouco mais com ele sobre sua vida, sua comunidade e a Arqueologia. A entrevista que se segue apresenta alguns dos pontos por nós discutidos.
\end{abstract}

Palavras-chave: Comunidade quilombola de Galeão; Arqueologia; Identidade; Ancestralidade; VI Semana Internacional de Arqueologia - Discentes MAE/USP.

"Eu resisti, resisto e vou continuar até o fim [...]" Silvio Campos

" Doutorando, Laboratório de Estudos Interdisciplinares sobre Tecnologia e Território, do Museu de Arqueologia e Etnologia da Universidade de São Paulo (LINTT-MAE-USP). <fabio.almeida@usp.br>

${ }^{* *}$ Doutoranda, Museu de Arqueologia e Etnologia da Universidade de São Paulo (MAE-USP).

<mborgespedroso@usp.br>

${ }^{* * *}$ Sócio fundador, Associação de Moradores de Galeão (AMEGA), Galeão, Cairu, Bahia. <silvestrems@live.com>

\section{Introdução}

Com seu jeito espontâneo e irreverente, o guarda ambiental e conselheiro tutelar Silvio Campos trouxe a VI Semana Internacional de Arqueologia - Discentes MAE-USP importantes reflexões sobre a realidade das comunidades quilombolas no Brasil e, em especial, da comunidade de Galeão ${ }^{1}$, onde ele reside, em Cairu, na Bahia.

1 A Vila de Galeão está localizada na ilha de Tinharé, uma das vinte e seis ilhas que compõem o município de Cairu, no estado da Bahia. 
Durante sua participação na mesa "Arqueologias Quilombolas", com muito bom humor, simpatia e respeito, Silvio dividiu suas inquietações e suas paixões pessoais. O público teve a oportunidade de conhecer e de aprender com uma pessoa que trabalha ativamente pela sua comunidade e que se preocupa diariamente com os desdobramentos futuros.

Entre outros aspectos, a relevância da apresentação de Silvio residiu no fato de mostrar uma perspectiva própria de um quilombola sobre a arqueologia e seus possíveis desdobramentos. Além de dar voz a um membro de uma comunidade quilombola, a apresentação de Silvio, ao lado da de outros pesquisadores, evidenciou a importância da pluralização dos discursos dentro das universidades e da construção de diálogos para problematizar nosso entendimento sobre a arqueologia. O público, formado majoritariamente por profissionais da área ou estudantes universitários, pôde aprender sobre outras formas de entender a arqueologia e pôde ter contato com o discurso de uma pessoa que não estudou arqueologia, mas que convive diariamente com materiais e sítios arqueológicos e que está muito engajada com o tema.

Durante a entrevista concedida, Silvio contou um pouco mais sobre sua história e sobre suas experiências com a arqueologia e com a vida. Para ele, a arqueologia tem desempenhado um papel significativo e fundamental no fortalecimento de sua comunidade e tem se relacionado diretamente com uma busca e avivamento da ancestralidade.

A entrevista com Silvio foi pensada a partir de três eixos principais: (1) a sua relação pessoal com a arqueologia; (2) a importância da arqueologia e seus desdobramentos dentro da comunidade de Galeão; e por fim, (3) a sua participação na VI Semana Internacional de Arqueologia - Discentes MAE/USP. Na primeira parte, Silvio relata um pouco sobre sua vida e motivações relevantes para impulsionar seu interesse pela arqueologia, ancestralidade, história, estudo dos materiais e envolvimento na pesquisa arqueológica. Dessa forma, aproximamo-nos das narrativas da história oral do entrevistado, do seu universo, dos seus saberes e de suas experiências, que culminaram nos trabalhos que ele realiza hoje na sua comunidade. Na segunda parte, apresentamos um panorama geral sobre a localidade e as suas características históricas e, também, sobre o processo de titulação de autorreconhecimento como comunidade quilombola e o potencial da arqueologia como ferramenta para o fortalecimento desse processo e da identidade quilombola. Por último, na terceira parte Silvio conta sobre sua participação na mesa "Arqueologias Quilombolas", na VI Semana Internacional de Arqueologia -Discentes MAE/USP.

Vale ainda ressaltar que os trechos da entrevista transcritos neste artigo passaram pela revisão de Sílvio, e foram ajustados para eliminar os vícios de linguagem, sem, no entanto, desviar ou alterar os conteúdos das falas. No mais, todo o artigo foi escrito, revisado e aprovado pelos três autores, cabendo a nós toda a responsabilidade pelo conteúdo que se segue.

\section{Dos cacos antigos para a arqueologia: as vivências e os entrelaçamentos arqueológicos}

A arqueologia e a história, pouco a pouco, se fizeram presentes no imaginário de Silvio e em grande parte graças à sabedoria maternal. Elas se entrelaçaram com a sua vida muito cedo pois, desde pequeno, a sua curiosidade fora nutrida e instigada pelos "casos antigos" que sua mãe, Dona Delzuita Sena Campos da Silva, de 79 anos, lhe contava. A preocupação e a sabedoria da mãe - ele exalta - em contar as vivências para seus filhos contribuíram para construir essa ponte com as suas "raízes". Silvio relembra que, tanto ele quanto seus irmãos foram ensinados sobre o passado da família por meio dessas narrativas e de onde eles extraíram suas primeiras referências: "essa referência de nossos parentes e das nossas raizes foi passada por nossa mãe quando falava sobre sua vivência, seu passado".

As histórias de Dona Delzuita, que remetiam ao passado, aguçaram seu interesse e indagações. Além dessas narrativas, Silvio nos conta que outros fatores, durante a infância, impulsionaram seus futuros interesses. 
Arqueologia, comunidade, ancestralidade e outros assuntos para pensar a identidade quilombola R. Museu Arq. Etn., 34: 194-205, 2020.

As experiências vividas, tanto em família quanto em sociedade, marcaram e transformaram sua forma de ver e de sentir o mundo. Ele ressalta que o fato de ser uma pessoa vitimada pela poliomielite pode ter contribuído para os rumos por ele tomados.

Silvio nasceu na Vila de Galeão, localizada na ilha de Tinharé, no município de Cairu, na Bahia, em 1972, por um parto doméstico, assistido pela parteira da comunidade. Naquele mesmo ano, um surto de poliomielite havia se espalhado pela região e, aos 9 meses de idade, Silvio foi acometido pela doença. A precarização do sistema de saúde dificultou o diagnóstico e o tratamento de Silvio. A região carecia de assistência médica e de acesso às imunizações, aos tratamentos de doenças etc. Ele relata que, na época, a vacinação existia, mas era restrita ao continente e não chegava até as ilhas: "tinha vacinação apenas no continente. Eles [os médicos] não vinham para as ilhas do arquipélago".

Com os olhos marejados, Silvio saúda Dona Delzuita e Sr. Salvador Rosa da Silva, seu pai, por nunca terem desistido dele já que, apesar do diagnóstico desenganador, recebido durante o primeiro atendimento, e das diversas dificuldades, eles buscaram outra alternativa. Ele nos narra como seu pai remou, com ele e sua mãe, em uma canoa até a sede do município em Cairu, onde ele foi diagnosticado corretamente e, aos poucos, com o tratamento, superou o estado crítico da doença. Contudo, ele nos conta que, apesar do tratamento, não conseguiu andar antes dos cinco anos. Ainda hoje, ele tem restrições de mobilidade, mas isso não o impede de realizar seus trabalhos e viagens.

A infância e as experiências de Silvio aconteceram em dois cenários diferentes, pois sua família havia se mudado para Vitória, no Espírito Santo, quando ele ainda era pequeno. Assim, sua infância se dividiu em dois momentos: a escola, em Vitória, e as férias, em Galeão. Aos seis anos, Silvio começou a frequentar a escola e aos sete retomou o contato com Galeão, durante a pausa no calendário escolar. Ele recorda que, quando criança, a Vila de Galeão era um lugar mágico. Ele e seus irmãos esperavam ansiosamente pelas férias, para passarem os dias em Galeão.
Apesar da longa e penosa viagem e da falta de infraestrutura, como energia elétrica, água encanada e lugar para dormir, eles sentiam liberdade animada pelo ambiente familiar. Ali era onde eles podiam andar na rua sem medo, pescar siri, pegar caranguejo no mangue, passear de canoa, tomar banho no rio e colher caju na mata, ter contato com a natureza e brincar como crianças, pois "era aqui que tínhamos nossa liberdade, nossas raizes".

Além das aventuras pela paisagem, Silvio também recorda da convivência em família:

Mais de vinte pessoas frequentavam a casa de minha avó [...] era uma vivência muito saudável, muito boa, tanto pelos valores transmitidos, como pela tranquilidade do lugar compartilhado. Esse lugar era como se fosse outro mundo para nós. Quando eu voltava para Vitória, parecia que eu havia vivido um sonho. Embora faltasse água encanada e o conforto que tínhamos em Vitória, a liberdade que sentíamos em Galeão era como um sonho. Esse sentimento ficou marcado como lembrança desse lugar [...] e também as conversas dos mais velhos, as caçadas de meu irmão, os fumeiros, os camarõos, os peixes secados ao sol [...] as lamparinas, os potes de barro, moringas e talhas, que armazenavam as águas [...].

A tranquilidade e a segurança encontradas por Silvio em Galeão contrastavam com as dificuldades vividas em Vitória. Na escola, sofria com o bullying de outras crianças por ser diferente, por ser uma pessoa com deficiência. Segundo Silvio, essas situações enfrentadas, durante a infância, moldaram sua personalidade e fizeram com que ele se tornasse uma pessoa introspectiva e fechada, contudo, observadora e questionadora ele ressalta. $\mathrm{O}$ fato de ter se tornado observador é apontado, por ele, como importante para os caminhos trilhados. A sua curiosidade pelas histórias aumentava à medida que ele analisava mais e mais o mundo ao seu redor:

a partir desse momento, creio que me tornei uma pessoa muito mais introspectiva [...] fechado, porém, muito observador e questionador. [...] Eu tinha meu mundo particular. Isso contribuiu, de certa forma, para eu me 
tornar uma pessoa observadora. Certamente, isso contribuiu também para essa grande questão da arqueologia e da ancestralidade.

Até começar a frequentar a vila, aos 7 anos, Silvio se relacionava com Galeão por meio dos relatos da mãe. Em Vitória, ele e seus irmãos estavam distantes fisicamente de suas familiares, com pouca ou quase nenhuma sociabilização de pessoas próximas com relação parental. Assim, as histórias de sua mãe encurtavam as distâncias entre o presente e a cultura ancestral e os conectavam com esse passado. Além disso, elas contribuíam para o estímulo da curiosidade de Silvio e para a construção de suas identidades que, segundo ele, se relacionavam muito com a cultura indígena. Dona Delzuita criou os seis filhos em uma terra distante da sua origem. Apesar da parceria e do companheirismo de seu marido, Sr. Salvador, certamente, ela sentia falta de suas raízes, seus pais, irmãos, tios, tias e amigos.

Para amenizar esse $b_{a n z o^{2}}$, ela contava histórias aos filhos, quando relembrava momentos de sua vida e relatava casos de seus antepassados.

\section{Minha mãe tinha essa preocupação de} contar as vivências dela para mim e para meus irmãos. Isso se revelou de grande sabedoria. Porque, você imagine um bando de retirantes?! Nós morávamos aqui na Vila de Galeão. Ela tinha 4 filhos [quando] nos mudamos para Vitória, no Espírito Santo. Lá nós não tínhamos nenhuma referência de origem. Então, a referência de nossos parentes e das nossas raizes foi nossa mãe que nos passou através das histórias sobre sua vivência, seu passado. Ela falava sobre a cultura e a história. Então, isso tudo certamente contribuiu para o meu atual interesse e minhas indagações.

Certamente, o cenário dessas histórias era a Vila de Galeão e o arquipélago de Tinharé, onde Dona Delzuita nasceu e viveu antes de ir para Vitória. Assim, desde pequeno, Silvio

2 Banzo é uma derivação da palavra mbanza, que no idioma quimbundo significa "aldeia” (Oda 2007). No Brasil, durante o período escravagista, o termo ficou conhecido como sinônimo do sentimento de saudade, melancolia, tristeza que o africano sentia de sua terra natal e, também, aversão à privação de sua liberdade em um lugar desconhecido. adquiriu conhecimento sobre a história e a cultura da Vila de Galeão e da região, mesmo não morando lá. Ainda que distante, as histórias e os contos de sua mãe estimularam sua imaginação e o aproximaram do universo cultural de Galeão. Com a sabedoria de uma griô ${ }^{3}$, sua mãe lhe forneceu referenciais de um tempo e de um lugar tradicionalmente conhecidos. Ainda que distante, sua personalidade foi construída como parte das referências históricas da Vila de Galeão.

Por conta dessa bagagem cultural adquirida, Silvio se recorda que na infância sua identificação dialogava com a cultura indígena "era como se eu participasse", afirma, "aquela questão da cultura indígena me dizia muito, até mesmo quando criança”. Ele nos conta que, enquanto os colegas se interessavam pelos personagens de heróis da televisão, como o Homem-Aranha e Super-Homem, ele procurava em figuras como Zumbi dos Palmares um reconhecimento.

e uma coisa que me chamava muito a atenção é a questão da ancestralidade, era uma coisa que me chamava muito a atenção. Eu me recordo quando, na infância, eu tinha uma atenção muito voltada para a questão indígena, era como se eu participasse. Quando criança eu me identificava com aspectos da cultura indigena. Enquanto outros colegas falavam sobre Homem-Aranha e outros super-heróis, eu me identificava com outras figuras, como Zumbi dos Palmares, Tiradentes. Então, desde criança eu tinha muito interesse pela história. Pelas questões do passado. Creio que carrego esses questionamentos de infância. Por isso, para mim, a arqueologia, a história e a ancestralidade são questão tênues, bem próximas.

Mesmo morando alhures, todo o imaginário infantil de Silvio teve como referência a Vila de Galeão. No período que morou em Vitória, as férias eram momentos

3 Também grafado griot (com a forma feminina griote), essa denominação refere-se à função exercida por pessoas escolhidas para preservar e transmitir as histórias, conhecimentos, mitos, narrativas e canções do seu povo. Os griôs são pessoas de destaque na sociedade de diversos países africanos, principalmente na África Ocidental. 
Arqueologia, comunidade, ancestralidade e outros assuntos para pensar a identidade quilombola R. Museu Arq. Etn., 34: 194-205, 2020.

de retorno às suas origens, de busca pelo seu passado e pela sua ancestralidade. As viagens para Galeão eram um momento esperado para estar mais próximo de seus heróis e referenciais de pertencimento.

Silvio está ligado a vila desde pequeno e, ao longo dos anos, essa relação foi se tornando cada vez mais intensa e profunda. Seu interesse sobre o passado aumentou quando ele passou a reconhecer os materiais arqueológicos existentes na Vila de Galeão. Depois que ele adquiriu uma chácara na parte alta da vila, toda a vez que arava a terra para plantar, ele conta que encontrava fragmentos de barro, louça, pedra, talheres e bules de metal, fragmentos de vidro e outros materiais arqueológicos. Seu interesse por esses objetos antigos passou a ser conhecido pelos moradores de Galeão, e sempre que alguém encontrava um desses objetos levava ao Silvio para ele tecer algumas explicações sobre o artefato.

Como veremos, atualmente, Silvio está envolvido em uma pesquisa arqueológica, cujo interesse é entender mais sobre esse passado e tê-lo mais próximo por meio dos objetos, fragmentos, lugares, conversas com outros moradores mais velhos e escavações nos sítios arqueológicos. Suas palavras deixam transparecer a importância e o potencial dos estudos dessa materialidade que brota do solo onde vive.

No entanto, ele faz questão de afirmar que a importância da arqueologia em Galeão, enquanto estudo que busca conhecer o modo de vida dos povos que ali viveram, a partir da cultura material por eles deixada, transita no campo da ancestralidade e do pertencimento histórico e é ferramenta voltada para o fortalecimento coletivo.

Para mim, acho que tem uma ligação [...] não tem como separar! A arqueologia e ancestralidade estão muito bem ligadas, acho que uma complementa a outra... a partir do momento que você desenvolve esse estudo em um lugar, de certa forma, você está montando a história da vivência dos povos que ali viveram. Então, cada artefato daquele, cada fragmento, conta uma história. Para mim, isso está muito ligado à ancestralidade. Esses caquinhos contam muito de minha história, contam muito de meus antepassados. Por isso, para mim, existe uma ligação muito forte entre arqueologia e ancestralidade nesse tocante.

Mais do que apenas "estudo de cacos", como ele diz, as pesquisas arqueológicas na Vila de Galeão têm resultado em momentos de relembrar o passado, reviver eventos e momentos considerados corriqueiros, mas que são valorizados pela interpretação dos objetos e lugares, ganhando importância enquanto fatos que revelam a história da comunidade.

\section{Comunidade de Galeão, identidade e arqueologia}

Localizado na ilha de Tinharé, a Vila de Galeão faz parte da extensão administrativa do município de Cairu, juntamente com outras 25 ilhas de um arquipélago continental. A vila está voltada para o continente, de frente para a cidade de Valença, na região conhecida como Costa do Dendê, no estado da Bahia.

A poucos quilômetros de Salvador, essa região foi alvo da invasão europeia desde o início do período colonial. Beneficiado pela geografia característica de lagamar, o arquipélago de Tinharé recebeu embarcações de mercenários e piratas ingleses, viajantes e exploradores, bem como a esquadra holandesa, meses antes de atacar Salvador, em 1624. Para defender a região e dar guarda à sede da colonia, a coroa portuguesa levantou vilas e fortes na região desde o começo do século XVII. Assim, a sede de Cairu teve a igreja matriz construída no ano de 1600 , seguida da capela dedicada a São Francisco Xavier na Vila de Galeão, em 1626. Logo depois, em 1630, um forte foi construído na ponta da ilha de Tinharé, voltado para a capital baiana e para defender a boca do principal canal do lagamar. 
Fabio Guaraldo Almeida

Michelle Borges Pedroso

Silvio Campos

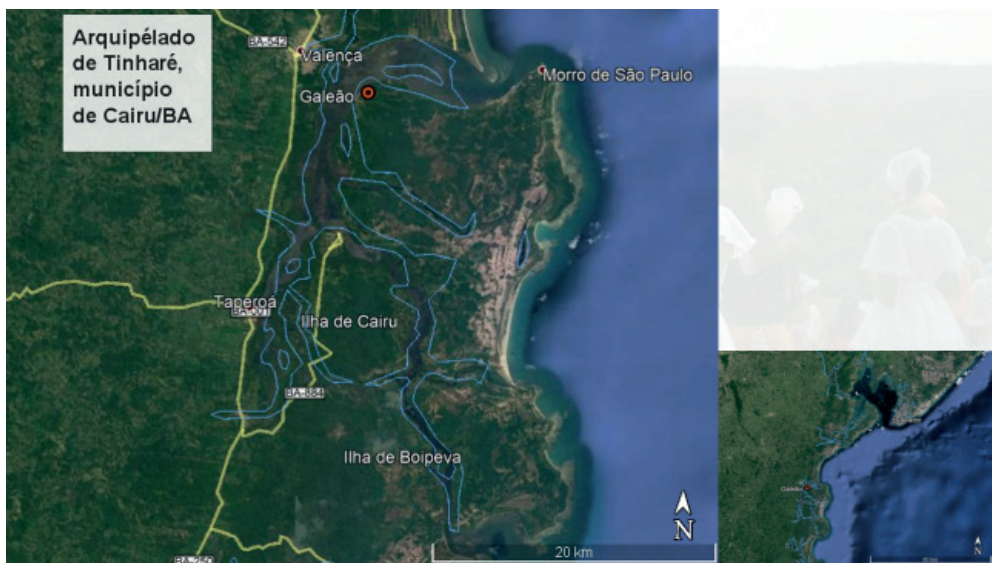

Fig. 1. Arquipélago de Tinharé, município de Galeão, BA.

Fonte: Google Maps, 2019.

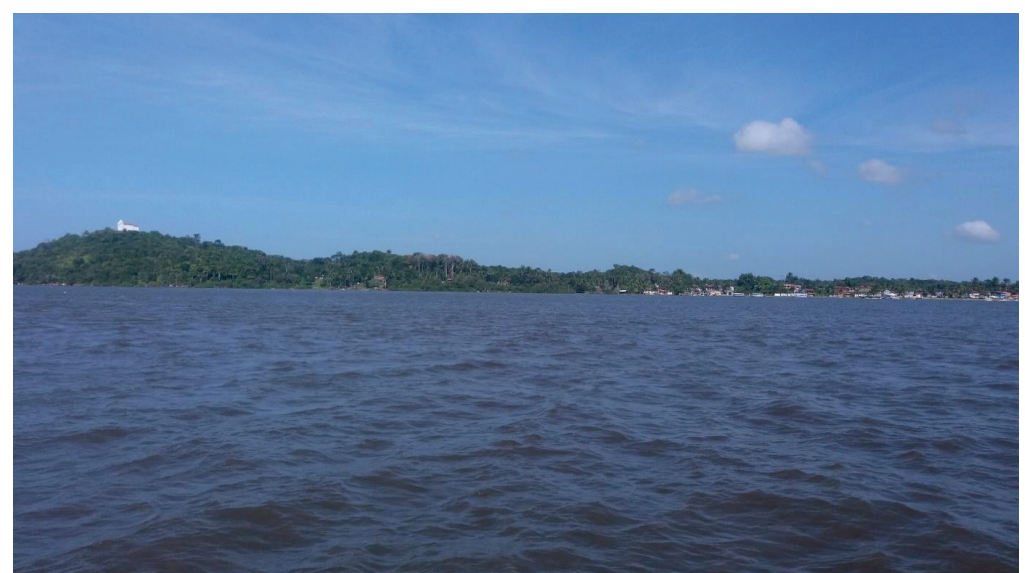

Fig. 2. A Vila de Galeão, com destaque para a igreja de São Francisco Xavier sobre o outeiro à esquerda na foto. Foto: Fabio Guaraldo.

Além dos ataques dos corsários e conquistadores holandeses, os primeiros colonos da região foram alvo dos ataques indígenas, principalmente dos aimorés que dominavam todas as terras da costa do continente, impedindo a conquista de seu território. Por isso, até a segunda metade do século XVII, as vilas coloniais da região estiveram restritas às terras insulares do arquipélago de Tinharé. Mesmo depois da invasão colonial nas terras do continente, as vilas formadas nas ilhas de Tinharé nunca ficaram desabitadas.

Como resultado desse processo, os atuais distritos do município de Cairu guardam inúmeros vestígios, como objetos e estruturas arquitetônicas, testemunhos da história colonial do Brasil. Alguns desses vestígios ainda são utilizados, como as igrejas, mosteiros e capelas, assim como também as fontes e os chafarizes. Outros vestígios são encontrados enterrados nos quintais e nas calçadas, ou depositados nos mangues pelo movimento da maré. Silvio reconhece a região como um sítio arqueológico a céu aberto pois, "em todo canto que você vai, você encontra material arqueológico. Aqui [em Galeão] a história é riquíssima e diversa: tem a questão de quilombo, dos jesuitas, tem a questão dos povos tradicionais da terra, os indigenas [...]”.

Já no século XVIII, toda a mão de obra escravizada na região era predominantemente 
Arqueologia, comunidade, ancestralidade e outros assuntos para pensar a identidade quilombola R. Museu Arq. Etn., 34: 194-205, 2020.

africana. Segundo Stuart Schwartz (2001: 224), a maior quantidade de escravizados em relação à população branca e a distância da capital baiana dificultaram a possível ajuda militar, facilitando as fugas dos escravizados e a formação dos quilombos. Atualmente, o município de Cairu possui seis comunidades autorreconhecidas como remanescentes de quilombos, entre elas a comunidade de Galeão.

A identidade quilombola da comunidade de Galeão foi certificada pela Fundação Cultural Palmares, em 2007, por meio da carta de autorreconhecimento da comunidade. Segundo Silvio, o processo de autorreconhecimento surgiu a partir de um grupo de pessoas ligado à Associação de Moradores (AMEGA) com apoio de Kátia Alexandria ${ }^{4}$, funcionária da Fundação Cultural Palmares na época. Kátia coordenou um levantamento histórico e estudos antropológicos na comunidade, por meio do qual aconteceu o autorreconhecimento como remanescente das comunidades de quilombo.

\section{O autorreconhecimento quilombola} veio da Associação de Moradores, um grupo de pessoas específico da comunidade. Após termos conhecimento dos nossos direitos, foi feito um levantamento [...] conseguimos através de documentos e através de estudos, esse autorreconhecimento como comunidade quilombola. Então, dessa forma, hoje Galeão tem o título de autorreconhecimento.

No entanto, Silvio revela que a comunidade é formada por moradores heterogêneos, dos quais nem todos "tem conhecimento do que significa ser autorreconhecido quilombola". Ele mesmo questionava a identidade quilombola, mesmo depois da pesquisa e da titulação da Fundação Cultural Palmares.

4 Katia Maria Alexandria Barbosa (28/01/1950 a 01/04/2017) foi professora e produtora cultural, formada em Filosofia pela Universidade Católica de Salvador (UCB). Ela foi membra fundadora da Sociedade de Proteção à Cultura Negra no Brasil (SECNEB) e Makota Mubenkiá no Terreiro Bate Folha. Atuou na Fundação Cultural Palmares de Salvador, facilitando o processo de autodenominação das comunidades quilombolas, principalmente na região da Costa do Dendê.
Eu me questionava como nossos antepassados constituiram um quilombo ao lado de uma igreja católica construida desde 1626. Sabemos, pela presença da igreja, que a Vila de Galeão foi fundada pelos portugueses. Então, como aqui pode ser considerado uma comunidade quilombola? Essas perguntas povoavam minha mente [...] eu tinha esse questionamento embora, de certa forma, eu tenha acompanhado e participado de todo o processo de autorreconhecimento como comunidade quilombola.

A dúvida de Silvio era legítima e revela muito da realidade presente em outras comunidades quilombolas. A identidade muitas vezes não é compartilhada de forma homogênea por todos. Os interesses e referências históricas na relação interna entre os membros da comunidade são divergentes, enquanto na relação com outras comunidades e interesses políticos, o discurso e, até mesmo, as performances dos membros da mesma comunidade se apresentam de forma homogênea (Carneiro da Cunha, 2009: 311-387).

Por outro lado, sabe-se que a memória e a história das comunidades afro-brasileiras passaram por um período de silenciamento deliberado ao esquecimento, quando o aparato governamental da República Velha direcionou sua política ideológica à adoção da cultura europeia como referência para a construção da identidade nacional. Apesar do intento, o pensamento colonial não conseguiu apagar a memória desses povos marginalizados, que hoje clamam pelo reconhecimento histórico para reivindicar seus direitos.

Nesse sentido, a arqueologia é crucial para Silvio. Ele percebe o potencial dessa ciência enquanto ferramenta para o fortalecimento da identidade quilombola, na luta pela reivindicação dos direitos coletivos:

a arqueologia é de suma importância. Ela promove a valorização e o conhecimento de nossa história. Nos empodera! Porque o povo que tem conhecimento de seu passado, certamente terá muito mais chances de 
projetar o seu futuro. Ele tem uma identidade, ele tem um porquê! Nesse sentido, eu creio que a arqueologia é de suma importância.

Ele continua relatando como o conhecimento ao mesmo tempo os une e os emancipa:

Especificamente para Galeão, a arqueologia nos empodera do conhecimento. Acho que o conhecimento é uma porta importantíssima para qualquer nação, para qualquer povo e individuo. Em Galeão, o conhecimento sobre o passado nos aproxima enquanto irmãos, pessoas de uma mesma origem. Galeão é uma comunidade muito heterogênea, com desafios para construir uma união entre os diferentes interesses. Então, a volta ao passado que a arqueologia permite a construção da identidade coletiva como irmãos. Isso abre possibilidade para que exista essa grande união e dissolva questões individuais - responsável pela heterogeneidade da comunidade - em uma identidade coletiva reforçada. Por esse caminho, a comunidade não fica tão dividida como está hoje. [...] Mas, apesar de ser um terreno muito fértil, [a arqueologia] ainda não é valorizado como se devia.

Apesar do potencial da região, inexistiam pesquisas arqueológicas antes de 2016.

Naquele ano, Silvio convenceu o arqueólogo Fabio Guaraldo Almeida em desenvolver um projeto de arqueologia na comunidade de Galeão. Assim, o projeto "Passado e presente na paisagem: temporalidade da paisagem quilombola na ilha de Tinharé" foi elaborado e iniciado sob a coordenação oficial de Fabio, mas com o envolvimento, participação e tomada de decisões do Silvio. Dessa forma, os objetivos do projeto eram diversos entre o arqueólogo e o quilombola, mas se encontravam na tentativa de entender o processo de formação da atual comunidade de Galeão e sua relação como os antigos quilombos presentes na documentação histórica da ilha de Tinharé.

A partir de sua participação na pesquisa arqueológica, Silvio começou a ouvir as histórias contadas pelas pessoas mais velhas da comunidade, a visitar sítios até então desconhecidos por ele, a participar de escavações e ter contato com métodos e procedimentos arqueológicos que lhe possibilitam fazer relações de tempos, lugares e pessoas, até então não imaginadas.

Então esse trabalho fez com que eu tivesse contato com as histórias das pessoas mais velhas da comunidade [...] assim, eu vim a entender porque Galeão é uma comunidade quilombola. Através desse trabalho, eu venho conhecendo pessoas e lugares que até então eu não conhecia. Desde criança eu não conhecia esses lugares. Então, foi a arqueologia que me proporcionou essa oportunidade e me trouxe esse conhecimento.

Silvio teve a oportunidade de conhecer novas pessoas e lugares em um ambiente que já lhe era familiar e destaca o afeto e a admiração por pessoas como Dona Amerinda, a moradora mais antiga de Galeão:

Aquela senhora humilde, simples, que não tem um conhecimento formal - mas detentora de uma sabedoria que faculdade nenhuma no mundo consegue ensinar - esclareceu minhas dúvidas, minhas grandes indagações, quando ela abordou e falou de onde ela veio.

Quando questionado sobre os impactos desse projeto na sua vida e na da comunidade, Silvio menciona a aceitação com que pessoas da administração pública municipal têm recebido a proposta do projeto de pesquisa e seus resultados. Quanto a ele, a divulgação da pesquisa tem resultado em sua participação mais ativa nas escolas a pedido dos próprios professores.

Há um grande interesse e uma grande movimentação sobre os resultados e desdobramentos dessa pesquisa arqueológica, não só no meu distrito [Galeão], que a gente observa claramente, mas também na sede do município [Cairu]. A pesquisa está tendo uma repercussão muito positiva, sim [...] Então, pelo resultado do nosso trabalho, eu venho sendo chamado por colégios para palestras, pelo pouco que sei, e me tornei referência histórica desse lugar. 
Arqueologia, comunidade, ancestralidade e outros assuntos para pensar a identidade quilombola R. Museu Arq. Etn., 34: 194-205, 2020.

Importante ressaltar que a relevância da arqueologia para as comunidades quilombolas, conforme defendido por Silvio, está na forma de fazer uma pesquisa de analogia histórica entre a trajetória da comunidade e seu território. Enquanto território quilombola, seus moradores possuem o sentimento compartilhado de pertencimento e sua identidade marcada nos lugares e caminhos que formam a paisagem da vila e do seu entorno.

Assim, Silvio entende a arqueologia como ferramenta para pensar a história de pertencimento e a escola como instituição de transmissão desse conhecimento, confluindo, assim, na construção da identidade quilombola. No entanto, ele identifica os impasses e as dificuldades desse desafio.

O problema é que as próprias professoras desconhecem a história. Quando o professor de história passa a mensagem aos alunos, ele não tem a preocupação de os empoderar, dizendo que eles, os alunos, fazem parte dessa história. Eles falam "o negro", "o índio", como uma coisa afastada. Eles não aproximam o aluno de sua história para construir sua identidade. Então, quando eu sou chamado para palestrar, tenho a oportunidade de passar esse sentimento de pertencimento para os alunos. Muitos falam que jovens e crianças são alienados de sua história, mas eu consigo de certa forma trazế-los à atenção. Eles ficam impressionados com os objetos que eu mostro e com as histórias que eu conto.

Silvio aprendeu o ofício de griô com sua mãe e hoje, as histórias são passadas adiante para os mais jovens, nas escolas. Por meio desses diálogos, crianças e adolescentes passam a conhecer mais sobre sua comunidade e sobre si mesmos. As suas palestras nas escolas têm repercussão positiva, elas despertam a curiosidade e o olhar das novas gerações e transformam a forma como os mais novos se relacionam com a vila e com os objetos que encontram pelo caminho.
Esta é a grande questão, eu os empodero pela história, porque eu os coloco como parte da história. Eu falo sempre a eles: "aqui corre sangue negro, aqui corre sangue indígena. Vocês são negros, nós somos a continuidade dessa história". Para a criança, isso é muito interessante. Elas vêm me procurar, vêm me questionar e quando algumas delas acham os artefatos antigos, elas me trazem. Até os professores me procuram para solucionar alguma dúvida. Então, de certa forma, percebe-se que nosso trabalho surte efeito.

Em vista de todas essas transformações e desses conhecimentos promovidos dentro da comunidade é que Silvio considera a arqueologia como peça-chave para movimentar sua comunidade e seus membros:

Então, a arqueologia é de suma importância [...] é uma engrenagem que vai funcionar para movimentar outras coisas, outras questões. Ela faz a resolução de questões, de grandes problemáticas sociais que nós vivemos até hoje. Por isso é uma ferramenta importantíssima.

Além de sua experiência com o projeto de arqueologia, Silvio faz questão de denunciar o desrespeito de alguns cientistas para com a comunidade. Segundo ele, outros pesquisadores frequentam a Vila de Galeão, onde desenvolvem projetos científicos principalmente no campo da biologia marinha. No entanto, nenhum desses projetos acadêmicos estão preocupados em envolver os moradores na pesquisa, ou sequer promovem a divulgação dos resultados para a comunidade:

Houve diversos programas de organizações estaduais, municipais e federais, que vieram para Galeão coletar dados e informações. [...] A população em geral vê esse povo como aproveitadores, porque eles sugam as nossas informações e não dão nada em troca. De certa forma, a gente se sente usado e isso provoca uma certa resistência [...] Afeta as instituições que procuram desenvolver trabalhos mais éticos. 


\section{Sobre a IV Semana Internacional de} Arqueologia Discentes - MAE/USP

A participação de Silvio na VI Semana Internacional de Arqueologia - Discentes MAE/USP foi encarada por ele como uma grande satisfação e reconhecimento pessoal. No entanto, Silvio confessa que o convite despertou alguns medos e receios. Por ser nordestino, preto e uma pessoa com deficiência física, ponderou que a cidade e a universidade o receberiam com hostilidade.

Nós temos esse estereótipo de ser mal recebido por ser nordestino e preto, além da minha deficiência física. Mas em momento algum eu senti discriminação. Eu fui muito bem recebido, fui muito bem tratado, não só pelos organizadores na Universidade, mas também na cidade. O pouco que eu caminhei pela cidade, eu fui muito bem recebido [...].

Silvio credita a Fabio, quem o sugeriu para a mesa, a motivação para aceitar participar do evento e integrar a discussão sobre arqueologias quilombolas, na mesa, ao lado da arqueóloga norte-americana Teresa Singleton e da arqueóloga brasileira Irislene Pereira Moraes.

O fato que me levou a participar do evento foi o trabalho realizado junto com o arqueólogo Fabio Guaraldo, [...] foi ele que me incentivou. Porque eu tinha o estereótipo [negativo] da cidade de São Paulo. [...] E lá, eu tive essa vivência, a mesa foi fantástica... eu só reclamo porque o tempo foi muito curto, porque você sabe que en falo pouco [risos]. Eu queria falar um pouco mais e toda hora eu tinha que olhar para o relógio, mas enfim foi muito prazeroso pra mim, foi uma experiência fantástica. Vou levar para o resto da minha vida. Você ser aplaudido de pé é fantástico.
No entanto, antes de finalizar a entrevista, Silvio completa com uma questão importante para ele:

Outra coisa que me levou a ir [ao evento] também é a questão das ameaças [ambientais] que o arquipélago vem sofrendo. [...] Esse arquipélago que é uma APA, uma área de proteção ambiental, fantástica, lindíssima que é muito cobiçada por especuladores imobiliários. Nossa região é o terceiro polo turístico da Bahia, perdendo só para Salvador e Ilhéus. Por isso, a especulação imobiliária é ferrenha. No entanto, enquanto APA existem normas que estão sendo desobedecidas [...]. Um exemplo é o projeto de construção de um grande resort planejado na Ponta dos Castelhanos, em cima das dunas, em cima de arrecifes, onde é uma área considerada pelo zoneamento da APA como área destinada para contemplação. Então são essas indagações e essas grandes ameaças aos povos tradicionais que me levaram para São Paulo, quase como um pedido de socorro.

Por fim, Silvio encerrou nossa conversa com um desabafo sobre as dificuldades enfrentadas, em decorrência dos seus trabalhos, e sobre sua resistência:

Eu me emocionei na minha fala por ter essa ligação muito forte com o meu povo negro, muito forte mesmo, é como chamamento. Passa um filme na minha cabeça, porque além de ser morador de Galeão, eu sou um agente ambiental concursado. Eu me mantenho integro perante a corrupção de compra de votos, de coronelismo, da realidade dos currais eleitorais. Então, a pessoa que tem ética, a pessoa que vai de encontro a corrupção, é muito maltratada. Durante meu trabalho como guarda ambiental e agora como conselheiro tutelar, eu sofro muito assédio moral, muita ameaça, coação, mas eu resisti, resisto e vou continuar até o fim, porque eu gosto do lugar. Eu resisto por isso, porque eu amo esse lugar. 


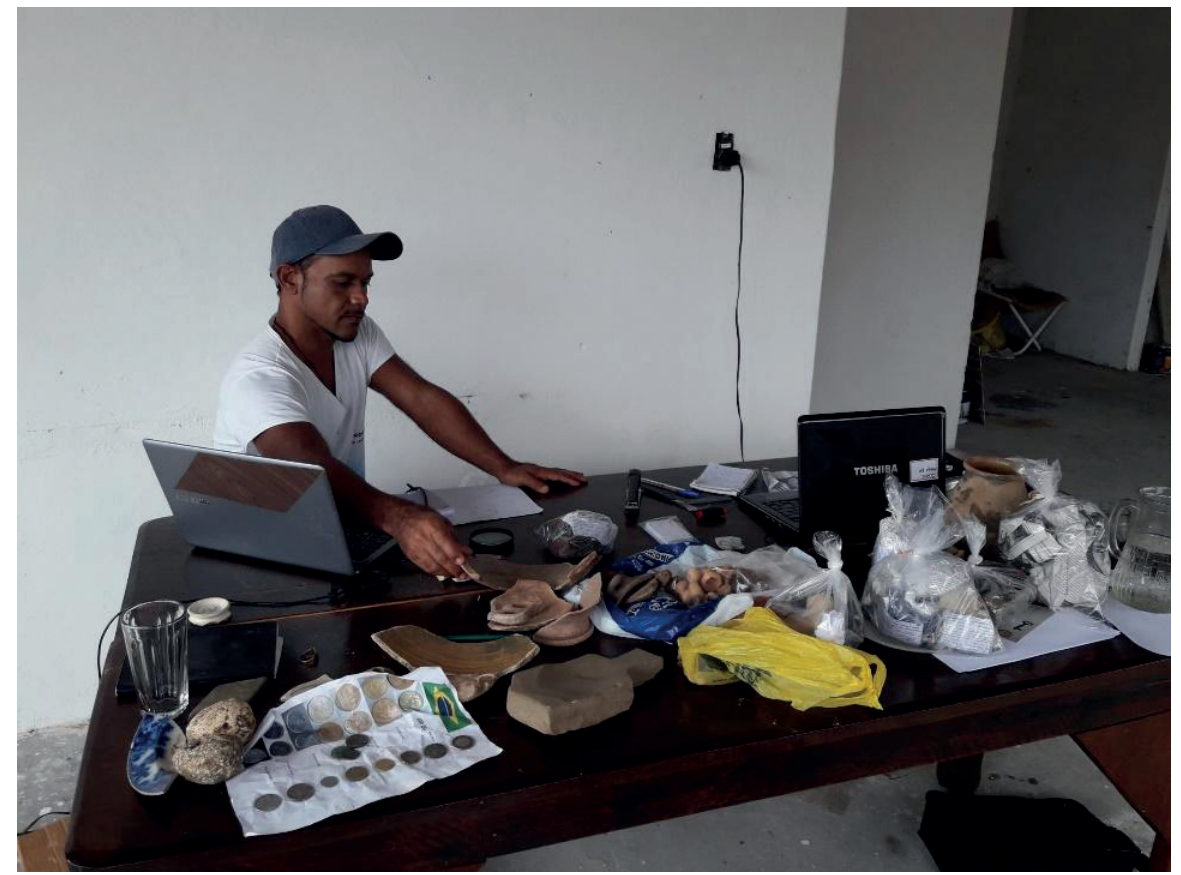

Fig. 3. Silvio Campos com o material que os moradores lhe entregam e ele usa em suas palestras e aulas nas escolas do município.

Foto: Fábio Guaraldo.

ALMEIDA, F.G.; PEDROSO, M.B.; CAMPOS, S. Archeology, community, ancestry, and other subjects to think about quilombola identity. R. Museu Arq. Etn. 34: 194-205, 2020.

Abstract: The theme of IV International Week of Archeology MAE/ USP Students turned around the pluralization of debates from perspectives that emphasized the concern with social and cultural contexts marginalized by societies, studies, institutions, etc. The outskirts became center and the discussions were builting from problems of forgotten and erased subjects and contexts. Thus, we emphasize the importance of talking about marginalized people, but even more so of the importance of letting they speak themselves and of creating possibilities for their voices to be heard. The table "Quilombola Archeologies" promoted debate between different perspectives, and Silvio Campos, along with other researchers, confirms the urgency of rethinking our hierarchical university structures. We need to promote and value other forms of knowledge production and realize that we always have much to teach, but we have much more to learn from others. Silvio taught us about his community from his narratives, knowledge and experiences. After his participation at the table, we talked a little more with him about his life, his community and archeology. The following interview presents some of the points we discussed.

Keywords: Quilombola community of Galeão; Archeology; Identity; Ancestry; VI International Archeology Week Students MAE/USP. 
Fabio Guaraldo Almeida Michelle Borges Pedroso Silvio Campos

\section{Referências bibliográficas}

Carneiro da Cunha, M. 2009. Cultura com aspas e outros ensaios. Cosac e Naify, São Paulo.

Oda, A.M.G.R. 2007. O banzo e outros males: o páthos dos negros escravos na Memória de
Oliveira Mendes. Revista Latinoamericana de Psicopatologia Fundamental, 10: 346-361.

Schwartz, S.B. 2001. Escravos, roceiros e rebeldes. Trad. Jussara Simões. Edusc, Bauru. 